\title{
Catalytic reductive amination of $\alpha$-ketocaboxylic acids as a useful route to amino acids
}

\author{
Albert S.C. Chan ${ }^{\mathrm{a}, \mathrm{b}, *}$, Chih-chiang Chen ${ }^{\mathrm{c}}$, Ying-chih Lin ${ }^{\mathrm{c}}$ \\ a Department of Applled Biology and Chemical Technology, Hong Kong Polytechnic, Hong Kong \\ ${ }^{\mathrm{b}}$ Department of Chemistry, National Chung Hsing University, Taichung, Tatwan \\ 'Department of Chemsstry, National Taiwan University, Taipel, Taiwan
}

Receıved 11 July 1994; accepted 7 September 1994

\begin{abstract}
The reductive amination of $\alpha$-ketocaboxylic acids using Raney nickel catalyst gave the desired amino acids in essentially quantitative yields. Both ammonia gas and aqueous ammonia as the aminating agents gave similarly high yields.
\end{abstract}

Keywords Ammo acid; Reductive aminatıon; $\alpha$-Ketocaboxylic acid; Phenylalanine, Raney nickel

\section{Introduction}

Amino acids are an important class of ingredients for the production of biologically active materials such as food additives and pharmaceuticals. Currently most amino acids are produced via three major routes [1]: (1) extraction from biological sources such as protein hydrolysates; (2) manufactured through fermentation [2]; (3) production from chemical processes such as the Strecker synthesis [3].

$$
\mathrm{RCHO}+\mathrm{NH}_{3}+\mathrm{HCN} \rightarrow \mathrm{RCH}\left(\mathrm{NH}_{2}\right) \mathrm{CN} \rightarrow \mathrm{RCH}\left(\mathrm{NH}_{2}\right) \mathrm{CO}_{2} \mathrm{H}
$$

Since most amino acids are used as supplements in animal feedstock or for human consumption, there is always concern about the residue cyanide in the Strecker synthesis. Besides, handling $\mathrm{HCN}$ is also a hazardous operation which is not popular among chemical workers. From a practical standpoint, it is desirable to develop safer and economically more attractive processes for the production of amino acids.

In the development of commercially useful technologies, very frequently great success comes from the development of effective technologies to take advantage

* Corresponding author. 
of new and/or economical feedstocks. In the late 1970's and early 1980's, there was a strong interest in the study of catalytic biscarbonylation of organic halides which gave $\alpha$-ketocarboxylic acids in high yields $[4,5]$.

$$
\mathrm{RCI}+2 \mathrm{CO}+\mathrm{OH}^{-} \stackrel{\mathrm{CO}_{2}(\mathrm{CO})_{8}}{\longrightarrow} \stackrel{\mathrm{H}}{\rightarrow} \mathrm{RC}(\mathrm{O}) \mathrm{CO}_{2} \mathrm{H}
$$

The advancement of the catalytic biscarbonylation technology has created an opportunity for the production of the valuable $\alpha$-ketocarboxylic acids at low cost. However, the technology was not commercially exploited because the demand for this type of material was not very high. In our opinion, if there is a simple method to convert the $\alpha$-ketocarboxylic acids to high value, large volume chemicals such as amino acids, the economic potential of the combined technologies will be very high. To this end we initiated a study of the catalytic reductive amination of $\alpha$ ketocarboxylic acids as an economical route to amino acids.

$$
\mathrm{RC}(\mathrm{O}) \mathrm{CO}_{2} \mathrm{H}+\mathrm{NH}_{3}+\mathrm{H}_{2} \rightarrow \underset{\mathrm{Cat}}{\rightarrow} \rightarrow \mathrm{RCH}\left(\mathrm{NH}_{2}\right) \mathrm{CO}_{2} \mathrm{H}
$$

The reductive amination of $\alpha$-ketocarboxylic acids with dihydrogen and ammonia has been previously studied by Fuenten and Schrage [6] and a $91 \%$ yield of phenylalanine lithium salt in the reductive amination of $\beta$-phenylpyruvic acid lithium salt using a palladium-on-carbon catalyst has been reported.

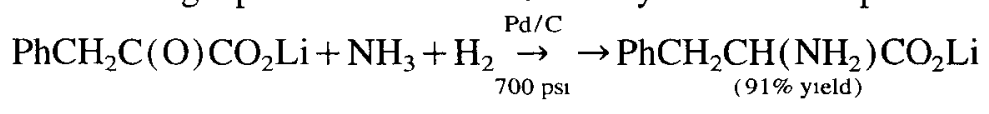

Phenylalanine is an important ingredient in the production of the popular artificial sweetener aspartame. In recent years, Toyo Soda in Japan and DSM in the Netherlands have joined forces to produce aspartame from DL-phenylalanine [7]. Therefore, an economical method for the production of DL-phenylalanine is of high commercial interest.

In this study we explored the possibility of developing an effective Raney nickel catalyst system for this type of reaction for the following reasons: (1) nickel-based catalysts are much more economical than noble metal catalysts (the cost of nickel is about 500 times lower than that of palladium); (2) the modification of Raney nickel catalysts with chiral materials such as tartaric acid has been reported to give effective asymmetric hydrogenation catalysts [8]. If the reductive amination of $\alpha$ ketocarboxylic acid is successful, there is a possibility to further modify the system to achieve our ultimate goal of asymmetric reductive amination.

\section{Experimental}

\subsection{General materials and procedures}

Except as noted, all purchased materials were of reagent grade and were used as received. All standard operations were carried out in the absence of air. All solvents were freshly distilled under nitrogen atmosphere before use. 
Reductive amination of $\beta$-phenylpyruvate with ammonia gas

A $100 \mathrm{ml}$ stainless steel autoclave was charged with $0.2 \mathrm{~g}$ of a $50 \%$ aqueous slurry of Raney nickel, $2.5 \mathrm{~g}$ sodium $\beta$-phenylpyruvate monohydrate, $60 \mathrm{ml}$ methanol, and about $10 \mathrm{~g}$ of ammonia. The mixture was stirred at $50^{\circ} \mathrm{C}$ under $200 \mathrm{psig}$ $\mathrm{H}_{2}$ for $24 \mathrm{~h}$. Upon completion of the reaction, the gas was vented and the solution was decanted. The catalyst was washed with three portions of $50 \mathrm{ml}$ of methanol. The filtrate and the washing were combined and the solvent was evaporated in a rotary evaporator. ${ }^{1} \mathrm{H}$ and ${ }^{13} \mathrm{C}$ nuclear magnetic resonance (NMR) analyses of the residue indicated a quantitative yield of phenylalanine sodium salt.

\section{Reductive amination of benzoylformic acid with aqueous ammonia}

A $100 \mathrm{ml}$ stainless steel autoclave was charged with $0.2 \mathrm{~g}$ of a $50 \%$ aqueous slurry of Raney nickel, $2.5 \mathrm{~g}$ benzoylformic acid, $60 \mathrm{ml}$ methanol, and $20 \mathrm{ml}$ of $37 \%$ aqueous ammonia. The mixture was stirred at $50^{\circ} \mathrm{C}$ under $200 \mathrm{psig} \mathrm{H}_{2}$ for 24 $h$. Upon completion of the reaction, the gas was vented and the solution was decanted. The catalyst was washed with three portions of $50 \mathrm{ml}$ of methanol. The filtrate and the washing were combined and the solvent was evaporated in a rotary evaporator. ${ }^{1} \mathrm{H}$ and ${ }^{13} \mathrm{C}$ NMR analyses of the residue indicated a quantitative yield of phenylglycine.

\section{Results and discussion}

In our initial study we focused our attention on the reductive amination of $\beta$ phenylpyruvic acid because the phenylalanine product is of substantial commercial interest.

When a 50\% water slurry of Raney nickel was used as catalyst, the reaction of $\beta$-phenylpyruvic acid with liquid ammonia and dihydrogen in methanol solvent was found to be very smooth. At $50^{\circ} \mathrm{C}$ and 200 psig operating pressure, an essentially quantitative yield of phenylalanine was obtained. The high yield in this reaction was somewhat surprising in light of the fact that $\beta$-phenylpyruvic acid itself is not a very stable compound. The decomposition of $\beta$-phenylpyruvic acid under relatively mild conditions to give benzaldehyde has been previously observed [9]. The high yield in the Raney nickel-catalyzed reductive amination was probably due to the rapid trapping of the $\beta$-phenylpyruvic acid by ammonia which alleviated the problem of the decomposition of the keto acid. This finding was extremely encouraging since both the cost of the catalyst and the operating conditions are easily manageable in an industrial setting. Under more severe conditions $\left(90^{\circ} \mathrm{C}\right.$, 850 psig $\mathrm{H}_{2}$ ), some of the $\beta$-phenylpyruvic acid (starting material) was hydrogenated to give $\beta$-phenyllactic acid (Table 1).

The reductive amination of $\beta$-phenylpyruvic acid was also achieved by using aqueous ammonia instead of ammonia gas. Equally high (essentially quantitative) yields of the phenylalanine product were obtained under similar conditions $\left(50^{\circ} \mathrm{C}\right.$, 
Table 1

Raney nickel-catalyzed reductive amination of $\operatorname{sodium} \beta$-phenylpyruvate ${ }^{\text {a.b }}$

\begin{tabular}{|c|c|c|c|c|c|c|}
\hline Raney $\mathrm{Ni}^{\mathrm{c}}$ (g slurry) & NaPPA (g) & Temp $\left({ }^{\circ} \mathrm{C}\right)$ & $P_{\mathrm{H}_{2}}(\mathrm{psig})$ & Time $(h)$ & Conv. (\%) & Selectivi ty (\%) \\
\hline 0.2 & 2.5 & 50 & 200 & 1.5 & 70 & $>98$ \\
\hline 0.2 & 2.5 & 50 & 200 & 20 & 100 & $>98$ \\
\hline 2.5 & 5.0 & 90 & 850 & 3 & 100 & $70^{d}$ \\
\hline
\end{tabular}

a The reactions were carried out in about $60 \mathrm{ml}$ methanol.

${ }^{\mathrm{b}}$ About $10 \mathrm{~g}$ of liquid ammonia was used in each experiment.

c The Raney nickel was purchased from Aldrich as a 50\% aqueous slurry and was used as received.

"The byproduct in this reaction was sodium $\beta$-phenyllactate.

Table 2

Raney nickel-catalyzed reductive amination of $\alpha$-keto acids

\begin{tabular}{llll}
\hline$\alpha$-Keto acid & Source of $\mathrm{NH}_{3}$ & Conversion $(\%)$ & Selectivity (\%) \\
\hline NaPPA & $37 \% \mathrm{NH}_{4} \mathrm{OH}$ & 100 & $>98$ \\
$p$-HO-PPA & $37 \% \mathrm{NH}_{4} \mathrm{OH}$ & 100 & $>98$ \\
Pyruvic acid & $37 \% \mathrm{NH}_{4} \mathrm{OH}$ & 100 & 97 \\
Benzoylformic acid & $37 \% \mathrm{NH}_{4} \mathrm{OH}$ & 100 & $>98$ \\
\hline
\end{tabular}

Reaction conditions: $0.2 \mathrm{~g} 50 \%$ aqueous slurry of Raney nickel; $2.5 \mathrm{~g}$ substrate; $60 \mathrm{ml}$ methanol (solvent); $15 \mathrm{~g}$ $37 \%$ aqueous ammonia; 200 psig $\mathrm{H}_{2} ; 50^{\circ} \mathrm{C} ; 20 \mathrm{~h}$.

200 psig $\mathrm{H}_{2}$ ). The simplification of the experiment by using aqueous ammonia has made this method more appealing to most synthetic chemists and consequently the synthesis should be of wider application.

After our success in the reductive amination of $\beta$-phenylpyruvic acid, it became clear to us that the synthetic method may be of wider use and a variety of high value amino acids may be produced via this simple and economical route. To test the scope of this chemistry, we also carried out the reductive amination of a wide range of keto acids including $\beta$-4-hydroxyphenylpyruvic acid, benzoylformic acid, pyruvic acid, etc. All of these reactions have been demonstrated to be highly efficient, indicating the wide applicability of this synthetic methodology. Details of the results are summarized in Table 2.

\section{Acknowledgements}

We thank the National Sciences Council, R.O.C. for a grant which supports part of the research. Part of the experiments were carried out at Monsanto Corporate Research. 


\section{References}

[1] G.C. Barrett (Editor), Chemistry and Biochemistry of the Amino Acids, Chapman and Hall, New York, 1985.

[2] K Yamada, The Microbial Production of Amino Acids, Wiley, New York, 1972.

[3] T Kaneko, Y. Izumi, I. Chibata and T. Itoh, Synthetic Production and Utilization of Amino Acids, Wiley, New York, 1974.

[4] R. Peron, US Patent 4152352 (1979), assigned to Rhone Poulenc.

[5] A.S.C. Chan, Stud. Surf. Sci. Catal., 35 (1988) 310.

16] H. Fuenten and K. Schrage, US Patent 4400533 (1983), assigned to Dynamit Nobel.

[7] K. Oyama and K. Kihara, ChemTech, (Feb. 1984) 100.

[8] J. Bakos, I. Toth and L. Marko, J. Org. Chem., 46 (1981) 5427.

[9] A.S.C. Chan, US Patent 4912255 (1990), assigned to Monsanto. 